\title{
Age-Related Differences in Erythropoietic Response to Recombinant Human Erythropoietin: Comparison in Adult and Infant Rhesus Monkeys ${ }^{1}$
}

\author{
JEANNE W. GEORGE, CAROL A. BRACCO, KEVIN M. SHANNON, G. JAMES DAVIS, \\ IAN L. SMITH, RODERIC H. PHIBBS, AND ANDREW G. HENDRICKX \\ California Primate Research Center, University of California at Davis, Davis, California 95616 [J.W.G., \\ C.A.B., A.G.H.], University of California at San Francisco, San Francisco, California 94143 [K.M.S., R.H.P.], \\ and R.W. Johnson Pharmaceutical Research Institute, Raritan, New Jersey 08869 [J.D., I.L.S.]
}

\begin{abstract}
Human recombinant erythropoietin (rHuEPO) was given i.v. to rhesus monkeys to compare its safety, erythropoietic effects, and pharmacokinetics in healthy adult and infant animals. Eighteen adult and 18 infant (9- to 15-d-old) monkeys were divided into three groups each of six animals. One group was given $250 \mathrm{U} /$ $\mathrm{kg}$ twice weekly, another was given $100 \mathrm{U} / \mathrm{kg}$ twice weekly, and a control group was given the drug vehicle for 6 wk. All animals were healthy throughout this period, and for 10 wk after that. Administration of r-HuEPO at these dosages did not produce any changes in leukocytes, platelets, urea nitrogen, bilirubin, creatinine, alkaline phosphatase, alanine amino transferase, $\gamma$-glutamyl transferase, and blood pressure in either age group. At $6 \mathrm{wk}$, both adult treatment groups had statistically significant increases in Hb concentration. The same dosages that produced these increases in $\mathrm{Hb}$ concentration in adults produced no changes in $\mathrm{Hb}$ concentration in infant monkeys. Despite active erythropoiesis, as determined by reticulocytosis and increased total body $\mathrm{Hb}, \mathrm{Hb}$ concentration decreased similarly in the infant treatment and control groups. Pharmacokinetic profiles were obtained at 5 wk of dosing. One h after administration, both doses of $\mathrm{r}-\mathrm{HuEPO}$ produced significantly lower serum r-HuEPO concentration in the infant monkeys compared with the adults. These differences appeared to be due to a larger volume of distribution of $r$-HuEPO in the infant monkeys. The $t_{1 / 2}$ of $r-H u E P O$ in circulation was the same in both age groups. (Pediatr Res 28: 567-571, 1990)
\end{abstract}

\section{Abbreviations}

EPO, erythropoietin r-HuEPO, recombinant human erythropoietin

The anemia of prematurity, a common complication of preterm birth, is characterized by a progressive fall in $\mathrm{Hb}$ concentration, reticulocytopenia, and bone marrow erythroid hypopla-

Received April 2, 1990, accepted July 12, 1990.

Correspondence: Jeanne W. George, D.V.M., Ph.D., Dept. of Medicine, School of Veterinary Medicine, University of California-Davis, Davis, CA 95616. NJ.

Supported by the R.W. Johnson Pharmaceutical Research Institute, Raritan,

i The opinions and assertions expressed herein are those of the authors alone and should not be construed as official or as necessarily reflecting the views of the Navy Department or of the Naval Service at large. sia (1). Affected babies may need transfusions because of clinical signs associated with impaired peripheral oxygen delivery (2). Inadequate production of EPO, the primary regulatory hormone for erythropoiesis (3), is thought to contribute to anemia of prematurity. Affected infants have low circulating levels of EPO (4-7) and normal numbers of peripheral blood erythroid burst forming units (8) and bone marrow colony forming units (9). Moreover, these erythroid progenitor cells respond normally to EPO in vitro (9). Administration of EPO has been proposed as a treatment for the anemia of prematurity (10).

The availability of r-HuEPO has led to the development of EPO replacement therapy in adults with chronic renal failure who are anemic because of inadequate EPO production. Treatment with r-HuEPO produces dose-dependent increases in $\mathrm{Hb}$ concentration with few side effects $(11,12)$.

Before undertaking any clinical trials of $\mathrm{r}-\mathrm{HuEPO}$ on infants with the anemia of prematurity, we believed it was important to give the drug to healthy infant experimental animals to determine whether any age-related differences existed in potential toxicity, erythropoietic effects, and pharmacokinetics. We chose infant rhesus monkeys (Macaca mulatta) because of their known hematologic similarities to human infants: a pattern of decrease of $\mathrm{Hb}$ concentration after birth followed by slow increase, and the rapid switch from fetal to adult $\mathrm{Hb}$ during the first months of life $(13,14)$. We report the results of a study in which adult and newborn rhesus monkeys received $\mathrm{r}$-HuEPO.

\section{MATERIALS AND METHODS}

Adult study. Eighteen sexually mature rhesus monkeys were assigned to two treatment and one control group, each having three male and three female animals. They were housed individually in metal cages in compliance with the standards of the Federal Animal Welfare Act and the Institute for Laboratory Animal Resources with a $12 \mathrm{~h}$ light/12 h dark schedule, a temperature of $20 \pm 6.7^{\circ} \mathrm{C}$, and an average humidity of $35 \%$. Water was supplied ad libitum. Monkey chow (15\% protein, Purina Mills, Inc., St. Louis, MO) was fed twice daily and supplemented with fresh fruit. All monkeys were healthy, as assessed by physical examination $3 \mathrm{~d}$ before treatment.

Monkeys received twice weekly i.v. injections of either 100 or $250 \mathrm{U} / \mathrm{kg}$ of r-HuEPO (Exprex, Amgen, Thousand Oaks, CA) or drug vehicle (human serum albumin in citrated saline) for 6 wk. All animals received intramuscular injections of $1.6 \mathrm{mg} / \mathrm{kg}$ of iron (Rogenic, Forest Pharmaceuticals, St. Louis, MO) biweekly, from $3 \mathrm{~d}$ before treatment until $1 \mathrm{~d}$ after ending treatment. Monitoring continued for 10 wk after the end of dosing. 
Monkeys were weighed once before, then weekly during the experiment.

Infant study. Eighteen 9- to 15-d-old rhesus monkeys weighing $400-650 \mathrm{~g}$ were assigned to two treatment and one control group, each having three males and three females. They were housed individually in plastic incubators and then in metal cages, in compliance with the standards of the Federal Animal Welfare Act and the Institute for Laboratory Animal Resources with a $16 \mathrm{~h}$ light $/ 8 \mathrm{~h}$ dark schedule, a temperature of $27.2 \pm 3.9^{\circ} \mathrm{C}$, and an average humidity of $47 \%$. From 2 to $12 \mathrm{wk}$ of age, human infant formula (Enfamil with Iron, Mead Johnson Nutritional Division, Evansville, IN) was fed several times daily. At age 5 to $6 \mathrm{wk}$, the diet was supplemented with fresh fruit, monkey chow (25\% protein, Purina Mills, Inc.), and orange-flavored drink (Tang, General Foods Corp., Rye, NY). Water was supplied ad libitum beginning at about $6 \mathrm{wk}$ of age. Food consumption was monitored and recorded about every $2 \mathrm{~h}$ until animals reached 5 to $6 \mathrm{wk}$ of age. Infant monkeys were healthy, as evaluated by physical examination within $3 \mathrm{~d}$ of study assignment.

Infant monkeys received $\mathrm{r}-\mathrm{HuEPO}$ or vehicle at the same dosage and on the same schedule as adults. They received 1.25 $\mathrm{mg} / \mathrm{kg} / \mathrm{d}$ of oral iron supplement (Fer-in-Sol Drops, Mead Johnson Nutritional Division) from $3 \mathrm{~d}$ before treatment until $1 \mathrm{wk}$ after its completion. Monitoring continued for $10 \mathrm{wk}$ after the last dose of r-HuEPO. Monkeys were weighed daily beginning 3 $\mathrm{d}$ before the first dose until $31 \mathrm{~d}$ after the final dose, then weekly for the remainder of the study.

Study procedures. Throughout the study, all monkeys were observed at least daily for signs of illness. Blood pressure was measured (Dinamap SX, Critikon, Inc., Tampa, FL) once pretreatment, then weekly during the study. All blood samples were collected by venipuncture from unsedated monkeys.

Complete blood counts were done on EDTA anticoagulated blood from adult and infant monkeys once pretreatment and once during wk 3,6,9,12, and 16. Red and white blood cells were counted electronically (Coulter model ZBI, Coulter Electronics Inc., Hialeah, FL), Hb was measured as cyanmethemolglobin (Coulter Hemoglobinometer, Coulter Electronics Inc.), reticulocytes counted by examination of slides after staining with new methylene blue, and differential white blood cells counted by examination of Wright stained smears. Platelets were counted by an automated method for adult monkeys (Baker 810 , Baker Instruments, Allentown, PA) and by hemocytometer after dilution with ammonium oxalate (Unopette, B-D Company, Rutherford, NJ) for infants. Alkaline phosphatase, alanine amino transferase, total bilirubin, urea nitrogen, creatinine, and $\gamma$ glutamyl transferase were measured using the same schedule as hematologic studies, (Gilford Impact-400E, CIBA Corning Diagnostics, Gilford Systems, Oberlin, $\mathrm{OH}$ ).

Total body $\mathrm{Hb}(\mathrm{TBH})$ was estimated for infant monkeys. Because blood volume of infant monkeys has not been measured, total body $\mathrm{Hb}$ was calculated on the premise that blood volume per $\mathrm{kg}$ body weight did not change during the experiment, and, therefore, the constant $\mathrm{X}$ could represent it in the following formula:

$$
\mathrm{TBH}(\mathrm{g})=\mathrm{Hb}(\mathrm{g} / \mathrm{dL}) \times \text { body wt }(\mathrm{kg}) \times(\mathrm{X})(\mathrm{dL} / \mathrm{kg})
$$

Pharmacokinetic studies. Serum samples for pharmacokinetic profiles were collected once before and approximately $1,5,10$, $15,24,32$, and $48 \mathrm{~h}$ after giving the 10 th dose of r-HuEPO or vehicle. Serum from blood samples $(0.5 \mathrm{~mL}$ in neonates and 1.0 $\mathrm{mL}$ in adults) was stored at -20 to $-40^{\circ} \mathrm{C}$ until assayed. A competitive binding RIA using antiserum to r-HuEPO obtained after immunization of New Zealand White rabbits was used to determine serum EPO concentrations. Because of the homology of EPO across species, endogenous rhesus monkey EPO crossreacted with $\mathrm{r}-\mathrm{HuEPO}$ in the assay. Serum taken after the $3 \mathrm{rd}$ and 12th doses of r-HuEPO was tested for the presence of antibodies against r-HuEPO by an ELISA that used r-HuEPO as the solid-phase coating. Hazleton Laboratories America, Inc. of Vienna, VA performed this assay.

The total amount of blood removed for all assays was approximately $14 \mathrm{~mL}$ for infant monkeys and $34 \mathrm{~mL}$ for adult monkeys.

This study was conducted according to good laboratory practice regulations as defined by the Federal Register, and prescribed by the Food and Drug Administration. The same manufacturer's lots of r-HuEPO were given to infants and adults. These lots were evaluated for activity before and after the study.

The Animal Use and Care Administrative Advisory Committee of the University of California, Davis approved all study procedures.

Statistical analysis. Differences between means of group data were tested using two-way analysis of variance for repeated measures. Differences over time were tested by one-way analysis of variance for repeated measures. Statistics were calculated using a computer program (StatView SE + Graphics, Abacus Concepts, Inc., Berkeley, CA). Serum concentrations of EPO $1 \mathrm{~h}$ after administrations were compared by unpaired $t$ test. A $p$ value of $<0.05$ was considered significant. All data are expressed as mean $\pm 1 \mathrm{SD}$.

\section{RESULTS}

No r-HuEPO-related changes occurred in total leukocyte, neutrophil, lymphocyte, and platelet counts, or in body weights in either adults (Table 1) or infants (Table 2). In both treated and control infant monkeys, total leukocyte and lymphocyte counts increased slowly throughout the study. Although adult but not infant monkeys had slight increases in eosinophils over time ( $p$ $<0.05$ ), there were no significant differences between treatment and control groups. Treated and control monkeys of both age groups did not differ in any of the serum chemistry analytes measured, or in blood pressure values. As they matured, infant monkeys that had received r-HuEPO remained healthy and were indistinguishable clinically from the control animals.

Erythrocytic parameters of adult monkeys are summarized on Table 1 . Hb concentration did not differ significantly among experimental groups of adult monkeys before treatment or after 3 wk of r-HuEPO administration. After $6 \mathrm{wk}$ of treatment, monkeys given either dose of $\mathrm{r}$-HuEPO had significantly higher $\mathrm{Hb}$ concentrations than control animals $(p<0.05)$. After that, the $\mathrm{Hb}$ concentrations in treated animals fell to those of the control group, with no significant differences found. Hb concentration rose slowly over the course of the study in the control group, becoming significantly higher than initial values at wk 9 . Although treated adult monkeys had slightly higher reticulocyte counts than control monkeys at wk 3 and 6 , these differences were not statistically significant. The three adult experimental groups had similar decreases in total reticulocyte count from an initially high level to a low at 9 wk. Mean corpuscular volumes did not differ among the adult test groups, although the overall mean of all test groups did vary over time.

In infant monkeys, treatment with r-HuEPO was not associated with any significant differences between treated or control monkeys in $\mathrm{Hb}$ concentrations or other measured erythrocyte parameters (Table 2). In the three test groups, the Hb concentration declined sharply by the 3rd week, then stabilized near that level. Reticulocyte counts reached a maximum at $3 \mathrm{wk}$, then decreased. Mean corpuscular volume decreased steadily throughout the study. Calculated total body $\mathrm{Hb}$ increased as animals grew, but r-HuEPO did not produce any significant differences between treated and control groups.

Pharmacokinetic profiles are summarized in Figure 1. Baseline serum EPO values were below the sensitivity of the assay $(5 \mathrm{mU} /$ $\mathrm{mL}$ ) in 15 of 18 of adult monkeys and in 16 of 18 infant monkeys, and did not increase in the monkeys given drug vehicle only. Serum concentrations of r-HuEPO at $1 \mathrm{~h}$ were significantly lower in infants than in adults given the same dosage $(p<0.05)$. Serum $\mathrm{r}-\mathrm{HuEPO}$ levels in adult monkeys $1 \mathrm{~h}$ after receiving $100 \mathrm{U} / \mathrm{kg}$ 
r-HuEPO IN ADULT AND INFANT MONKEYS

Table 1. Adult hematologic and wt values

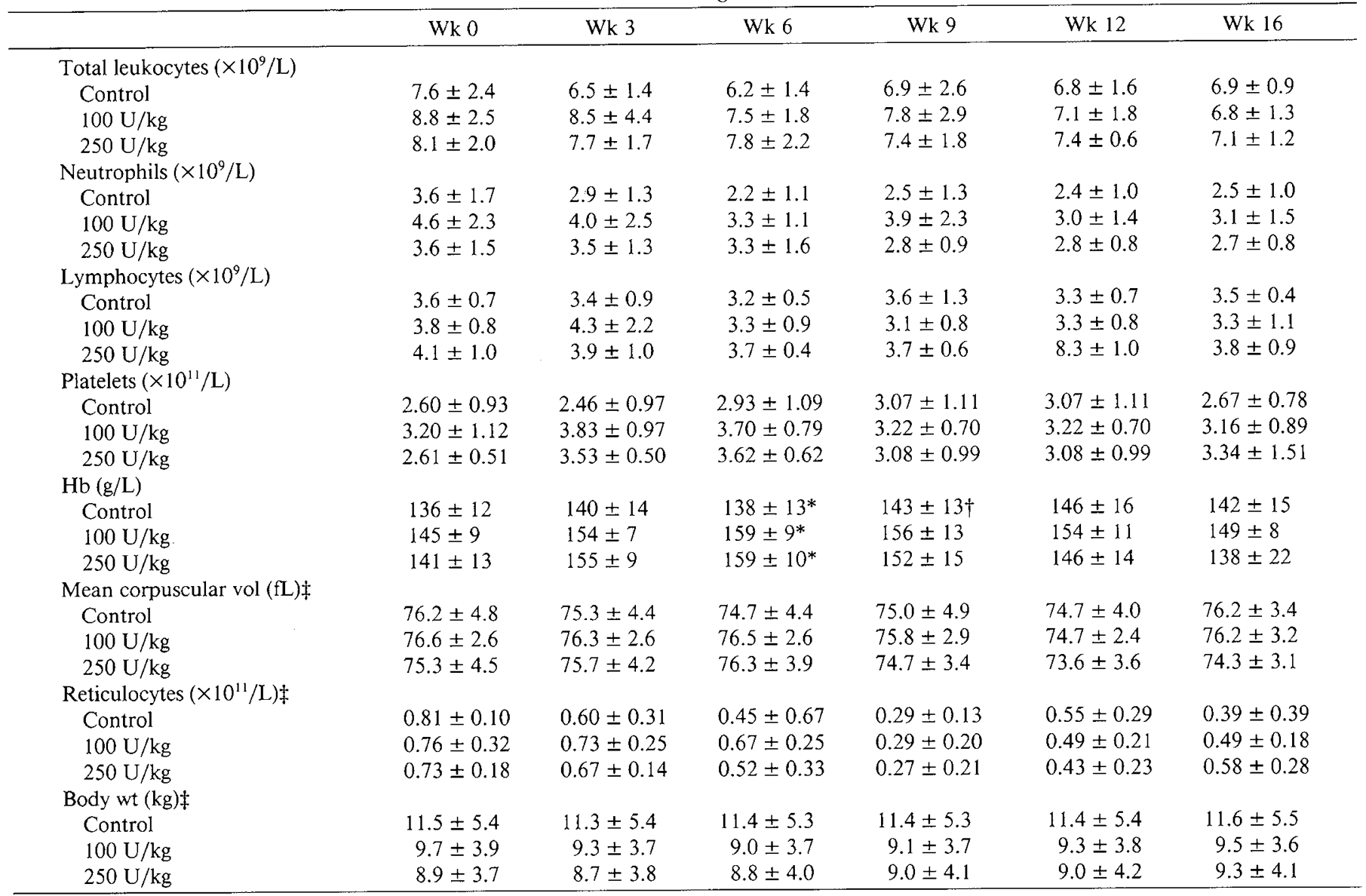

* Significant differences between treated and control groups $(p<0.05)$.

+ Control values significantly higher than baseline, but no significant difference among groups $(p<0.05)$.

$\ddagger$ Significant differences in overall mean over time, but no significant differences among groups $(p<0.05)$.

approximated those found in infant monkeys that received 250 $\mathrm{U} / \mathrm{kg}$. The apparent volume of distribution, estimated by dividing the dose by the zero-h serum r-HuEPO concentration, as extrapolated from the curve in Figure 1 , was $35.7 \mathrm{~mL} / \mathrm{kg}$ in adults and $77 \mathrm{~mL} / \mathrm{kg}$ in infants. A 2.5 -fold increase in i.v. dose resulted in a proportionate increase in peak serum concentrations in both infant and adult monkeys. The overall mean $t_{1 / 2}$ of all experimental groups for $\mathrm{r}-\mathrm{HuEPO}$ in serum was $2.5 \pm 0.4 \mathrm{~h}$, with no significant difference found among the groups. None of the monkeys developed antibodies to r-HuEPO.

\section{DISCUSSION}

We administered r-HuEPO to rhesus monkeys to compare its safety, erythropoietic effects, and pharmacokinetics in healthy infant and adult animals. No adverse effects were associated with $\mathrm{r}-\mathrm{HuEPO}$ treatment in either infant or adult monkeys. Neither thrombocytosis, thrombosis, nor hypertension, reported complications of $\mathrm{r}-\mathrm{HuEPO}$ therapy in human renal failure patients (11, $12,15)$, developed in either adult or infant monkeys. No rHuEPO-associated leukocyte changes occurred in either age group. The only unexpected change in adult monkeys was a slight increase in eosinophil count during the experiment. A possible explanation is a low-grade allergic reaction to either the human serum albumin in the drug vehicle or the peptonized iron, two compounds administered to all adult animals.

We did not find significant differences in $\mathrm{Hb}$ concentrations between treated and control infant monkeys after either 3 or 6 wk of r-HuEPO administration. Lack of erythropoietic response to administered $\mathrm{r}-\mathrm{HuEPO}$ in infant monkeys was not the result of an intrinsic inability of rhesus erythroid progenitors to respond to that compound. Both adult treatment groups had significant increases in $\mathrm{Hb}$ concentration, as have other adult experimental animals given $\mathrm{r}-\mathrm{HuEPO}$, including mice (16), dogs, rats, and cynomolgus monkeys (R. W. Johnson Pharmaceutical Research Institute, unpublished data).

The significantly lower serum concentrations of $r-H u E P O$ in infant monkeys given the same dose as adults may have contributed to this age-related difference. The volume of distribution that we calculated for adult monkeys $(35.7 \mathrm{~mL} / \mathrm{kg})$ is close to their reported plasma volume (17). Similarly, the volume of distribution for EPO in adult sheep and rats equals their plasma volumes $(18,19)$. If $\mathrm{r}-\mathrm{HuEPO}$ also distributes to the plasma volume in infant animals, one would expect lower serum concentrations per unit of dose because infants have larger plasma volume per $\mathrm{kg}$ than adults of the same species. We did not find any published values for plasma volume of infant rhesus monkeys. The volume of distribution calculated for $\mathrm{r}-\mathrm{HuEPO}$ in infant rhesus monkeys $(77 \mathrm{~mL} / \mathrm{kg})$ is larger than plasma volume reported for infants of other animal species (17) and human infants (20).

Other explanations for this large calculated volume of distribution would be that r-HuEPO distributes in infant monkeys to a larger space than plasma volume, or that the first rate of removal was missed in this study by the necessity of a limited sampling schedule in these small animals. Plasma volume measurements on infant rhesus monkeys and more detailed pharmacokinetic measurements during the first hours after administration would be helpful in determining which of these explanations is correct.

Differences in serum concentration, however, cannot completely explain the age-related difference we found. Infant mon- 
Table 2. Infant hematologic and wt values

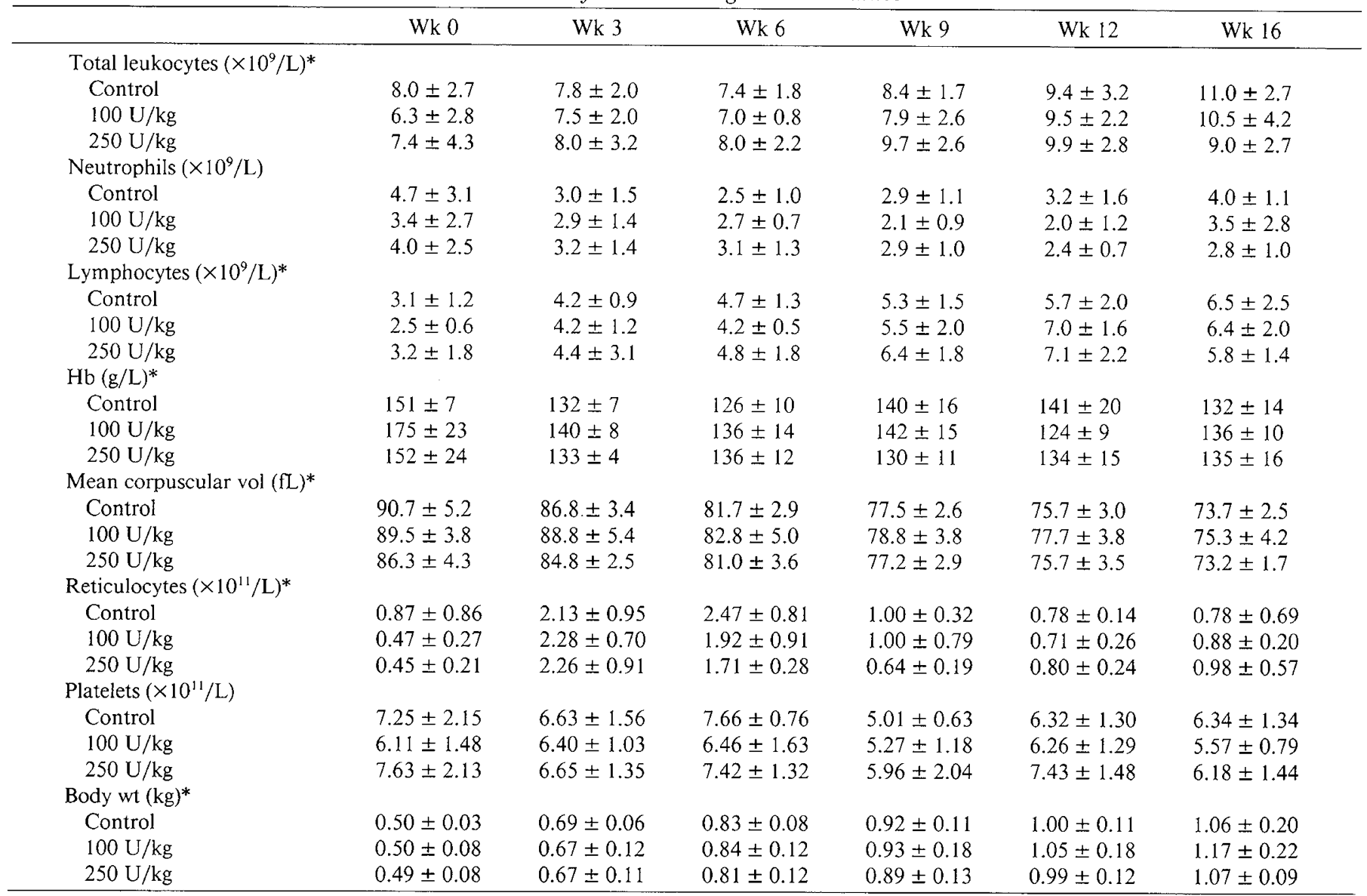

* Significant differences in overall mean over time, but no significant differences among groups $(p<0.05)$.

keys that received $250 \mathrm{U} / \mathrm{kg}$ of r-HuEPO achieved similar peak serum levels as adult monkeys that received $100 \mathrm{U} / \mathrm{kg}$, yet they did not increase erythrocyte production above control values, as the adults did. Less iron might have been available to the infant monkeys for increased erythropoiesis. Iron deficiency is a major cause of r-HuEPO therapy failure in patients with chronic renal disease $(11,12,15)$. Infant animals of any species are in precarious iron balance resulting from multiple demands of growth, expanding blood volume, and limited amounts of storage and dietary iron (21). Erythropoiesis was active in the infant monkeys, as shown by reticulocytosis and increasing total body $\mathrm{Hb}$. Those given r-HuEPO might have lacked enough iron to increase erythropoiesis above that being stimulated by their endogenous EPO. We based iron supplementation on the recommended level for human term infants of $2 \mathrm{mg} / \mathrm{kg}$ total dietary iron (22). Infant rhesus monkeys may need higher levels of iron because of their shorter gestation period, smaller size, and more rapid growth rate. We did not perform any laboratory tests to measure iron balance because we wanted to keep the volume of blood removed from these small animals to a minimum.

Low-grade iron deficiency might have also existed in the adult monkeys. Hb concentration increased slowly in control monkeys, which received supplemental iron. Recently, subclinical iron deficiency has been recognized as a problem in adult monkeys at the California Primate Research Center (23). The use of parenteral iron, which is available for erythropoiesis sooner than oral iron, may have allowed the adult monkeys to increase $\mathrm{Hb}$ during r-HuEPO administration. Although iron deficiency did not prevent response to r-HuEPO, it may have blunted it; both treatment groups had similar $\mathrm{Hb}$ concentrations during $\mathrm{r}-\mathrm{HuEPO}$ administration.

It is possible that the active erythroid bone marrow of infant monkeys responds differently to r-HuEPO than the marrow of adult rhesus monkeys. The target cells of r-HuEPO might have been exposed to fewer than the needed number of EPO molecules for stimulation, resulting from the combination of larger dilutional space and greater numbers of erythroid progenitor cells in infant monkeys. Although it is possible that erythroid progenitors of infant monkeys are intrinsically less responsive to r-HuEPO than adult cells, there are no data to support this hypothesis. Erythroid progenitors cultured from human fetuses and premature and term babies respond at least as well to r-HuEPO as adult progenitors $(8,9,24)$. Although no in vitro work using rhesus monkey bone marrow has been published, fetal baboon bone marrow cultures stimulated by r-HuEPO had a pattern of erythroid burst growth similar to that seen in adults (25). Studies giving higher doses of r-HuEPO to infant monkeys supplemented with more iron, as well as in vitro experiments to compare the patterns of erythroid progenitor growth from adult and infant rhesus monkeys over a range of $\mathrm{r}-\mathrm{HuEPO}$ concentrations, would help determine whether iron or age-related erythroid progenitor insensitivity are important limiting factors in their response to $\mathrm{r}-$ HuEPO.

Although the pattern of erythropoiesis in healthy infant rhesus monkeys differs from that in anemic premature babies, the results of our study provide new information that augments limited data from recent studies on use of r-HuEPO in anemia of prematurity $(26,27)$. The lack of any adverse effects of r-HuEPO in infant monkeys supports the concept that further placebocontrolled clinical trials of r-HuEPO therapy in anemia of prematurity are warranted. Particularly important was the finding that infant monkeys given r-HuEPO at doses higher than those given to human infants did not develop neutropenia or thrombocytosis. Both were reported in seven premature infants given 


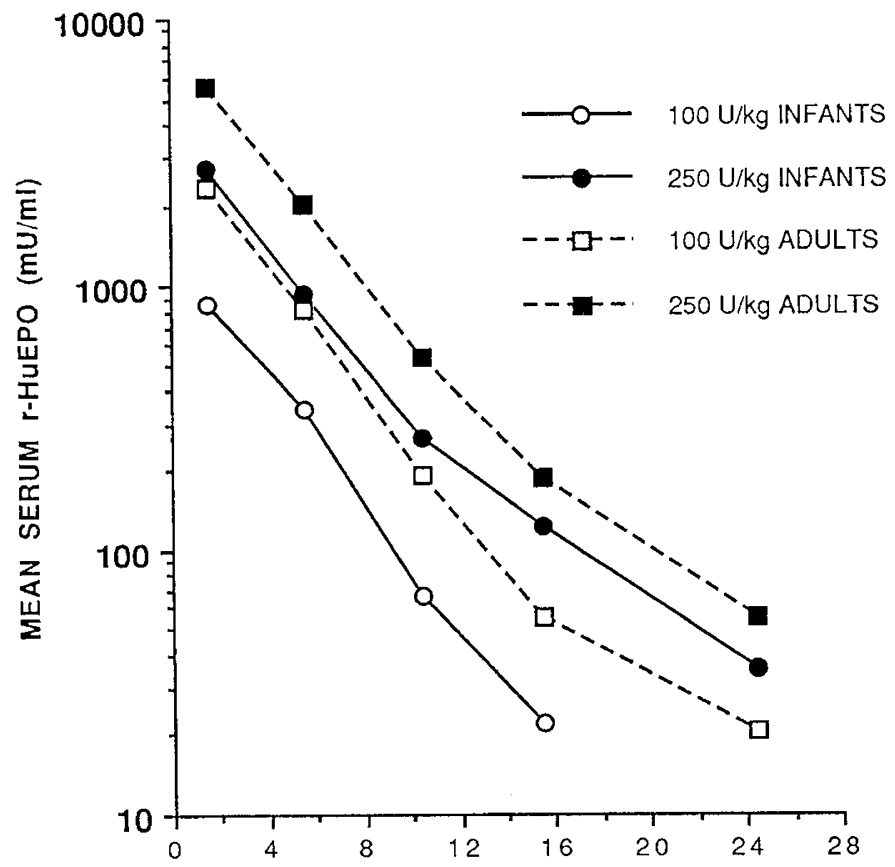

TIME (hours)

Fig. 1. Mean serum r-HuEPO concentration. The $100 \mathrm{U} / \mathrm{kg}$ dose in adults produces approximately the same concentration at $1 \mathrm{~h}$ as the 250 $\mathrm{U} / \mathrm{kg}$ dose in infants. The slopes of all elimination curves are similar.

r-HuEPO in an uncontrolled study (27), although they did not occur in a larger, placebo-controlled study (26). Secondly, the erythropoietic response to r-HuEPO of infants cannot be predicted from the responses of adults of the same species. Our data in infant rhesus monkeys are consistent with the observation that human premature infants given $\mathrm{r}-\mathrm{HuEPO}$ in doses known to be effective in adults had either no increase (26) or a very slight increase (27) in $\mathrm{Hb}$ production. Preterm human babies have large plasma volumes compared with adults; dosage schedules designed for adults may produce lower circulating $\mathrm{r}-\mathrm{HuEPO}$ concentrations, as we found in infant monkeys. Furthermore, iron deficiency occurred in some babies treated unsuccessfully with r-HuEPO (27). Higher amounts of iron, perhaps even parenteral iron, may need to be given during r-HuEPO therapy for optimal erythropoiesis in both infant rhesus monkeys and premature babies. When viewed together, our work and the two pilot studies of r-HuEPO therapy in anemia of prematurity are complementary, but leave some important practical and theoretical questions about its use in infancy unanswered. Erythropoiesis in infant rhesus monkeys may prove to be a useful animal model for further investigation of the use of r-HuEPO in premature babies.

Acknowledgments. The authors thank Alice Tarantal, Tammy Hendrie, Abbie Spinner, Robin Beards, Terry Buchholz, and Bud Goding for their help in this study.

\section{REFERENCES}

1. Wardrop CAJ, Holland BM, Veale KEA, Jones JG, Gray OP 1978 Nonphysiological anaemia of prematurity. Arch Dis Child 53:855-860

2. Dallman PR 1981 Anemia of prematurity. Annu Rev Med 32:143-160

3. Spivak JK 1986 The mechanism of action of erythropoietin. Int J Cell Cloning 4:139-166

4. Brown MS, Phibbs RH, Garcia JF, Dallman PR 1983 Postnatal changes in erythropoietin in untransfused premature infants. J Pediatr 103:612-617

5. Brown MS, Garcia JF, Phibbs, RH, Dallman PR 1984 Decreased response of plasma immunoreactive erythropoietin to "available oxygen" in anemia of prematurity. J Pediatr 105:793-798

6. Buchanan GR, Schwartz AD 1974 Impaired erythropoietin response in anemic premature infants. Blood 44:347-352

7. Stockman JA, Graeber JE, Clark DA, McClellan K, Garcia JF, Kevey REW 1984 Anemia of prematurity: determinants of the erythropoietin response. J Pediatr 105:786-793

8. Shannon KM, Naylor GS, Torkildson JC, Clemons GK, Schaffner V, Goldman SL, Lewis K, Bryant P, Phibbs R 1987 Circulating erythroid progenitors in the anemia of prematurity. N Engl J Med 317:728-733

9. Rhondeau SM, Christensen RD, Ross MP, Rothstein G, Simmons MA 1988 Responsiveness to recombinant human erythropoietin of marrow erythroid progenitors from infants with the "anemia of prematurity." J Pediatr 112:935-940

10. Stockman JA 1988 Erythropoietin: on again, off again. [editor's column] J Pediatr 1 12:906-908

11. Eschbach JW, Egrie JC, Downing MR, Browne JK, Adamson JW 1987 Correction of end-stage renal disease with recombinant human erythropoietin. N Engl $\mathrm{J}$ Med 316:73-78

12. Drueke T, Zins J: Naret C, Casadevall N, Goureau Y, Berehi L, Peterlongo F, Cataigne J-P, Zingraff J, Delons S, Kreis H, Varet B 1989 Utilization of erythropoietin in the treatment of the anemia due to chronic renal failure. Adv Nephrol 18:187-205

13. Martin DP, McGowan MJ, Loeb WF 1973 Age related changes of hematologic values in infant Macaca mulatta. Lab Anim Sci 23:194-200

14. Ketchen H, Brett I 1974 Embryonic and fetal hemoglobin in animals. Ann NY Acad Sci 241:653-671

15. Watson AJ 1989 Adverse effects of therapy of the correction of anemia in hemodialysis patients. Semin Neph 9(suppl 1):30-34

16. Egrie JC, Strickland TW, Lane J, Aoki K, Cohen AM, Smalling R, Trail G, Lin FK, Browne JK, Hines DK 1986 Characterization and biological effects of recombinant human erythropoietin. Immunobiology 172:213-214

17. Jain NC 1986 Schalm's Veterinary Hematology, 4th ed. Lea and Febiger, Philadelphia, p 91

18. Mladenovic J, Eschbach JW, Koup JR, Garvia JF, Adamson JW 1985 Erythropoietin kinetics in normal and uremic sheep. J Lab Clin Med 105:659663

19. Spivak JL, Hogans BB 1989 The in vivo metabolism of recombinant human erythropoietin in the rat. Blood 73:90-99

20. Oski FA 1987 The erythrocyte and its disorders. In: Nathan DG, Oski FA (eds) Hematology of Infancy and Childhood. WB Saunders, Philadelphia, pp 1643

21. Smith JE 1989 Iron metabolism and its diseases. In: Kaneko JJ (ed) Clinical Biochemistry of Domestic Animals. Academic Press, New York, pp 256273

22. Dallman PR 1987 Iron deficiency and related nutritional anemias. In: Nathan DG, Oski FA (eds) Hematology of Infancy and Childhood. WB Saunders, Philadelphia, pp 274-314

23. Mandell CP, George JW 1989 Effect of repeated phlebotomy on the iron status of the Rhesus monkey. Vet Clin Pathol 18:12(abstr)

24. Emerson SG, Thoma S, Ferrara JL, Greenstein JL 1989 Developmental regulation of erythropoiesis by hematopoietic growth factors: analysis on populations of BFU-E from bone marrow, peripheral blood and fetal liver. Blood 74:49-55

25. Eves EM, Heller P, DeSimone J 1989 Differences in burst morphology among baboon species. Exp Hematol 17:73-76

26. Shannon KM, Mentzer WC, Abels RI, Freeman P, Newton N, Thompson D, Sniderman S, Ballard R, Phibbs RH 1990 Recombinant human erythropoietin in anemia of prematurity: preliminary results of a double blind placebo controlled pilot study. Pediatr Res 27:269A(abstr)

27. Halperin DS, Wacker P, Lacount G, Felix M, Babel J-F, Aapro M, Wyss M 1990 Effects of recombinant human erythropoietin in infants with the anemia of prematurity. J Pediatr 116:779-786 